تقويم الأداء التدريسي لأعضاء الهيئة التدريسية في كلية التربية الرياضية من وجهة نظر الطلبة

\author{
د.أحمد قاسم محمد و صبري سليمان حسن \\ كلية التربية الرياضية، جامعة دهوك، اقليم كوردستان-العراق صماق فيمان
}

(تاريخ استلام البحث: 12 آذار، 2019، تاريخ القبول بالنشر: 19 حزيران، 2019)

الخلاصة

هدفت الدراسة التعرف على مستوى الأداء الثدريسي لأعضاء هيئة التدريس في كلية التربية الرياضية بجامعة دهوك ، ووالتعرف على دلالة التحاء

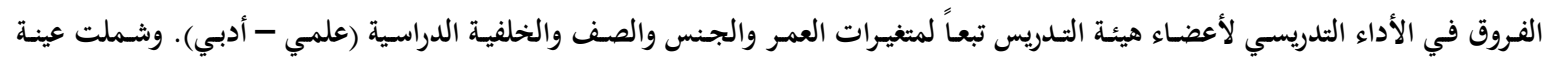

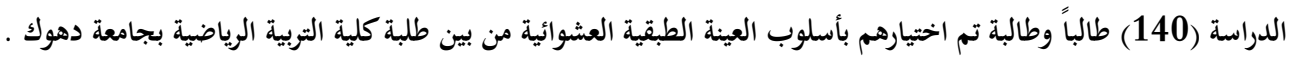

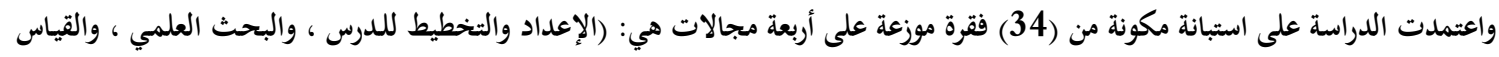

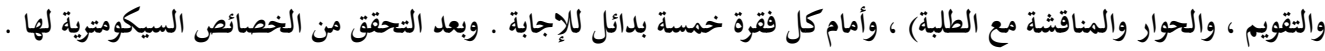

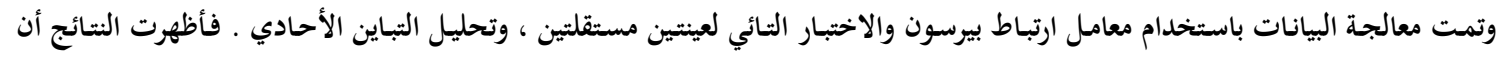

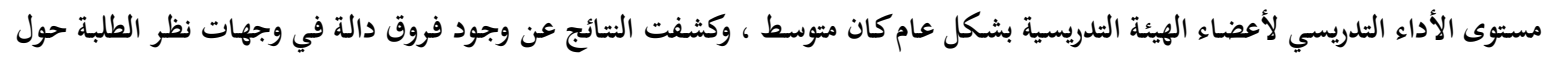

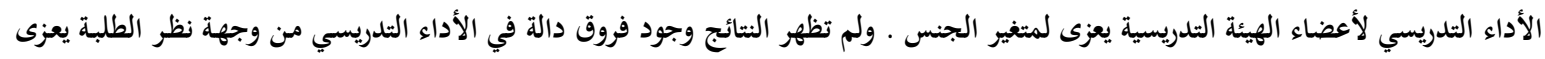

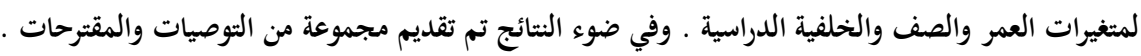

في البيئة الحالية التي تعمل بها مؤسسات التعليم العالي وانفتاحها

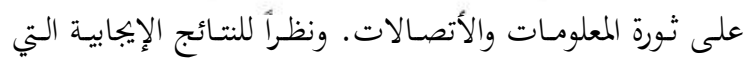
حققتها استخدام الشبكات في دعم ورفع كفاءة العملية التعليمة على المسـتوى العـالمي ، فقـــ تعـددت تطبيقـات التعلـيم عـبر

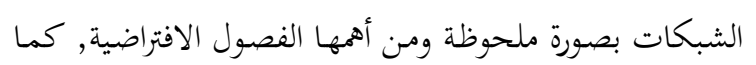
أنه قد بدأ الاعتماد على نظام الفصول الافتراضية, بعد تحقيقها

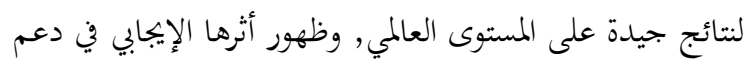

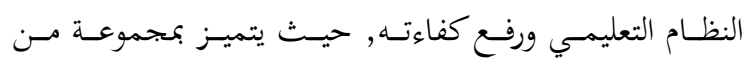

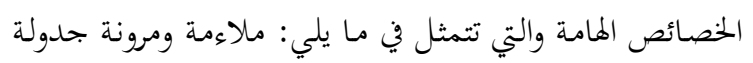

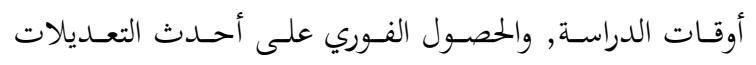

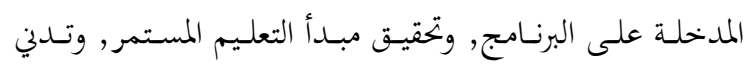

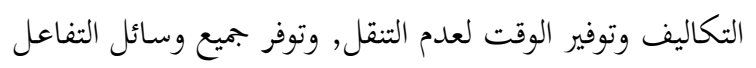
بين الطالب والتدريسي(زين الدين ، 2007 : 172) .

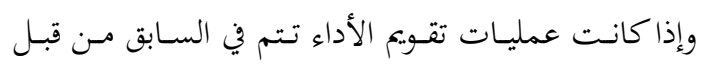

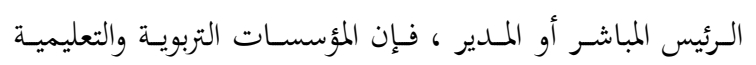

مقدمة

سعى مؤسسات التعليم العالي الى التميز في تقلديم خدماتما

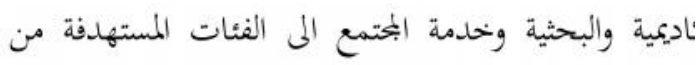
الطلاب ؛ لذا تبذل هذه المؤسسات قصارى جهدها لكي ولكي تنجح في استقبال الطلبة ، والعمل من أجل إعدادهم بشكل متميز من خلال تزويدهم بالمعارف والمهارات والخبرات العلمية

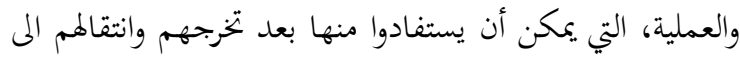

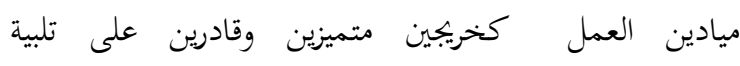

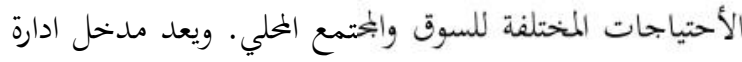
الجودة الشاملة احد الأسبقيات التنافسية الأساسية التي ينبغي ولئي المؤسسات التعليم العالي التركيز عليه من اجل تحقيق التميز والفاعلية (24: Kanji,1999 :الجراح وآخرون،2005 : 15). كما يعد عضو هيئة التدريس العنصر المحرك الأساسي في

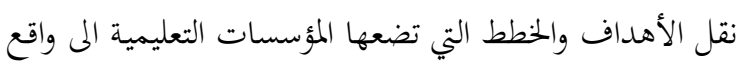

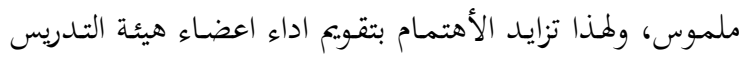


مستقبلا وعلى البختمع كله. كما تنعكس على حرص التدريسي

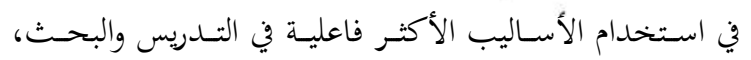

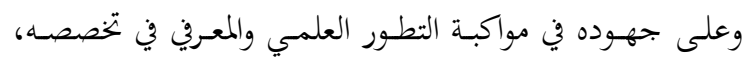

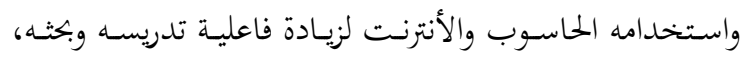

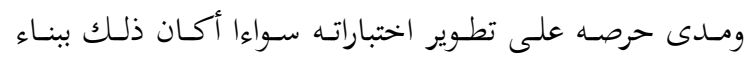

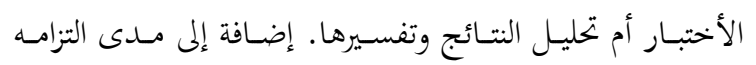

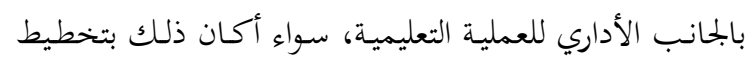

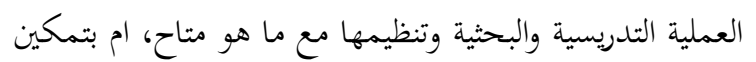

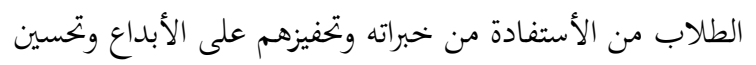

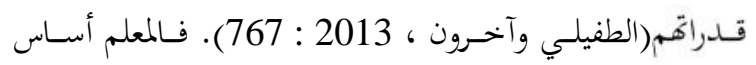
المنظومة التعليمية, وبمقدار قدرته وكفاءته, تكون فاعلية التعليم,

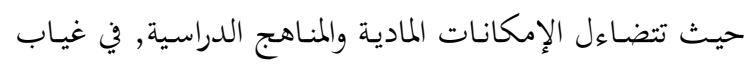

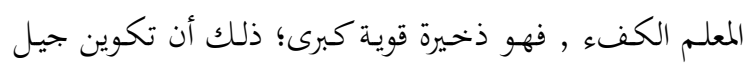

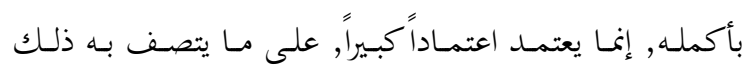
المعلـم, مـن سمـات شخصسية وتربويـة, تعينـه على أداء مهمتـهـ

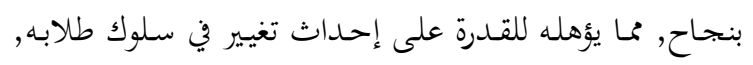

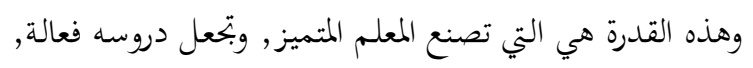
ذات أثر واضح, وتحقق النتائج المنشودة.

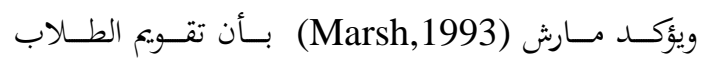

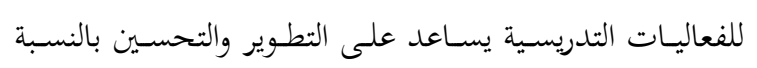

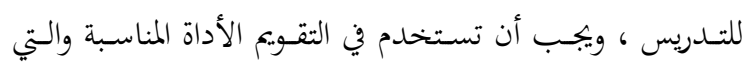
تتناسب في أبعادها ومحتواها وخصائص التدريس الجحامعي الفعال

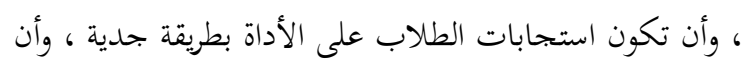

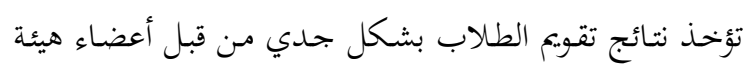

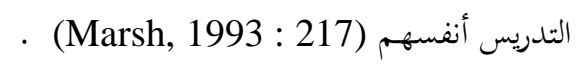
مشكلة الدراسة: تولي مؤسسات التعليم العالي في كل بلدان العالم مزيداً مـن المداس

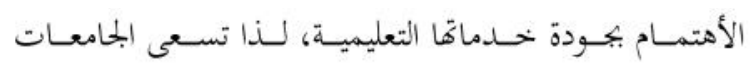
والكليات إلى توفير بيئة متميزة لكوادرها التعليمية في محاولة منها لحانيا

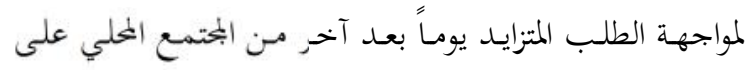
امداده بالخريجين القادرين على تلبية احتياجاته بكفاءة وفاعلية.

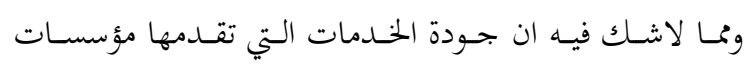

المعاصرة تعتمد على أساليب جديدة في تقويم الأداء ، ومن بين

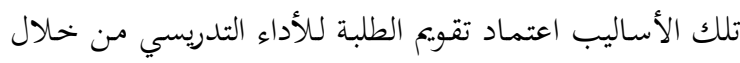
أخذ رأي الطلبة في عملية تقويم الأداء التدريسي في مادة دراسية لقدية معينة ضمن المنهج المقرر ، إلى جانب أساليب أخرى في تقويم

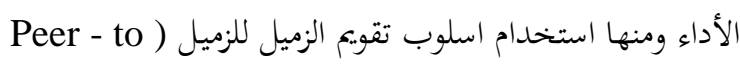

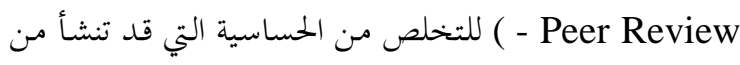
النموذج التقليدي، وكذلك لزيادة موضوعية عملية التقويم. وين هـذا السـياق يـأتي البحست الحسالي لتقـويم جـودة اداء

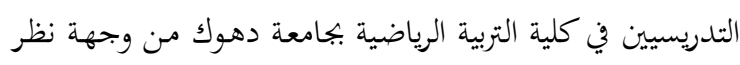

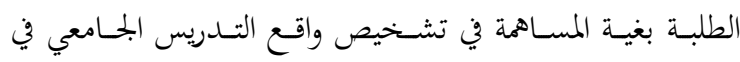

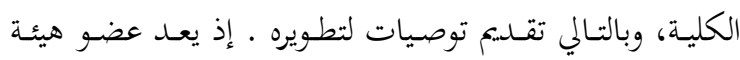
التدريس احسد العناصر الأساسية في العملية التعليمية، وقد زاد

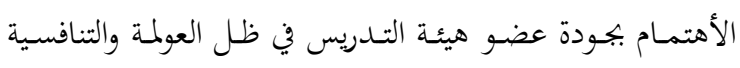

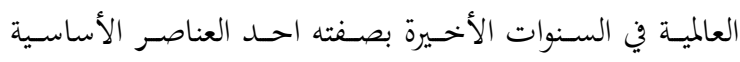
لضبط نوعية التعليم.

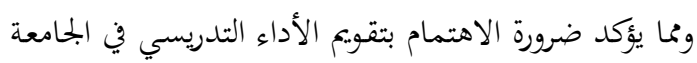

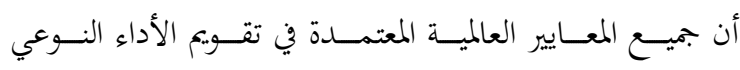
لمؤسسات التعليم العالي اشتملت على عنصر مشترك لبنها ، ألا وهو عضو هيئة التدريس، حيث ان حرص الجامعة على تقويم

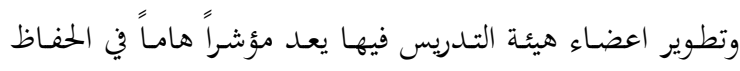

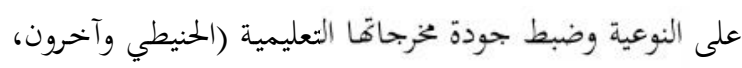

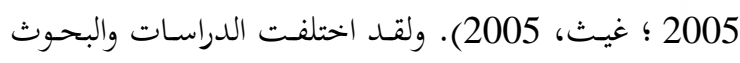
المنشورة في المعايير المستخدمة لتقويم عضو هيئة التدريس ، والتي

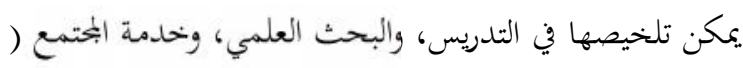
برنامج الأمم المتحدة للتطوير، 2005 ؛ حمدان، 2005).

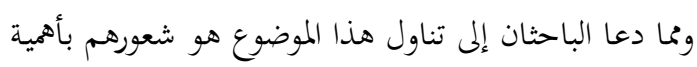
أخذذ تقويم الطلبة للأداء التدريسي لنظر الاعتبار ، لأفم أكثر

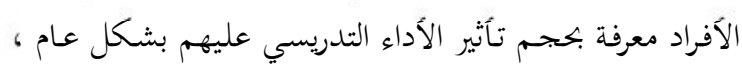
وفاعلية التدريس على وجه الخصوص. فالطلاب هم المستفيدين

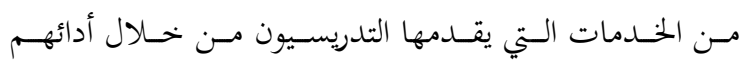

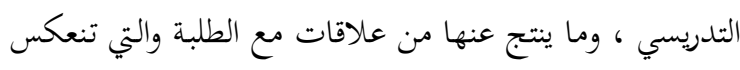
في المستقبل على شخصياقم ومؤسساتم التي سيعملون بهـا 
التعليمية على وضع برامج واتخاذ إجراءات معينة من أجل تدعيم

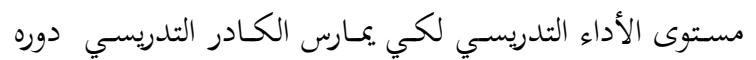

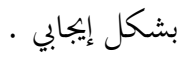

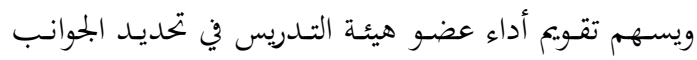

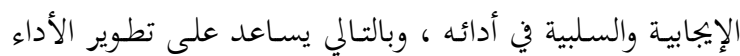
التدريسيسي لـه ، فيتجـهـ نحسو اسـتخدام الوسـائل الالكترونيسة

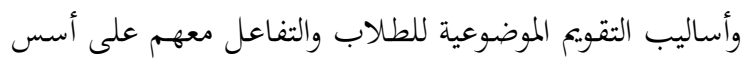
علمية سليمة (الحكمي ، 2004 : 20) . أهداف الدراسة : تمدف الدراسة الحالية التعرف إلى : 1. مستوى الأداء التدريسي لأعضـاء هيئـة التـدريس في كليـة التربية الرياضية بجامعة دهوك 2. دلالة الفروق في الأداء التدريسي لأعضاء هيئة التدريسمن دهوك وجهة نظر الطلبة تبعاً لمتغيرات:

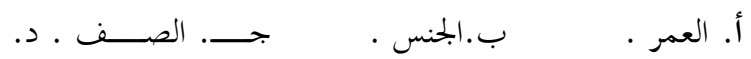
الخلفية الدراسية (علمي - أدبي).

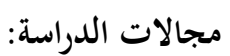

1. البحال البشري: تقتصر الدراسة الحالية على الطلبة المستمرين

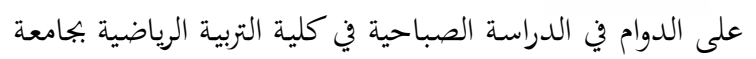
2. البحـال الزمـاني: الفصـل الدراسي الأول مـن العـام الدراسي 2019/2018م.

3. المحال المكاني : قاعات كلية التربية الرياضية بجامعة دهوك . تحديد المصطلحات: 1 يعرف دوانى Downi التقويم بأنه إعطلاء قيمـة لشيء مـا وفقاً لمستويات حددت سلفاً (أبو لبده ، 1996 : 63) .

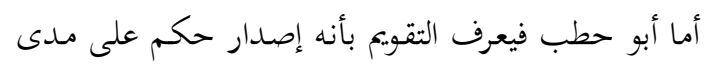

تحقيق الأهداف التربوية (أبو حطب ، 1980 ، 39 39) . 2.تقويم الأداء :
التعليم العالي تنعكس على اداء خريجيها في اسواق العمل، والتي

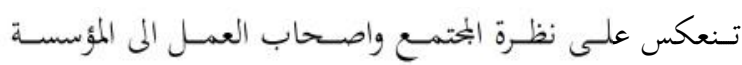

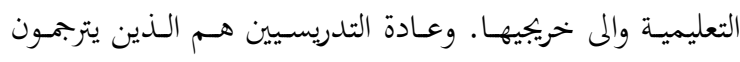

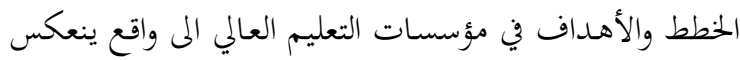
في اداء خريجيهم مستقبلا، وما يبنى على هذا من سمعة للخريجين

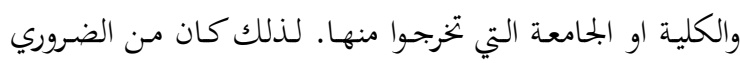

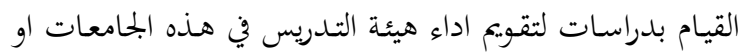

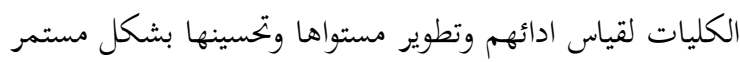

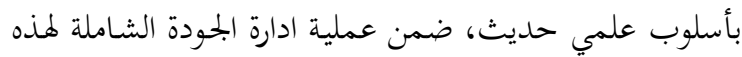

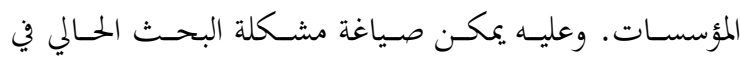
السؤالين الآتيين: مـا مستوى الأداء التدريسي في كلية التربية الرياضية بجامعة التئية

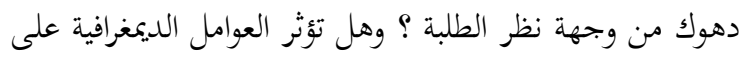

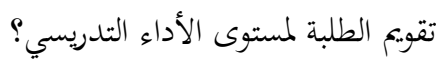

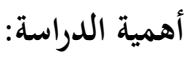
تكمـن الأهمية النظرية للدراسة الحالية في تناولها لمتغير مهم مـن المتغيرات التربوية ألا وهي الأداء التدريسي في كليـة التربية الرياضـية بجامعـة دهـوك، وقـد تسـهم هـذه الدراسـة في تقــليم مؤشرات دقيقة عن جوانب الأداء في هذه المؤسسة التعليمية ،

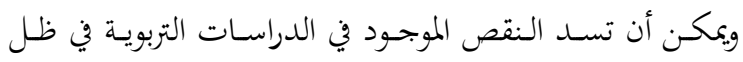

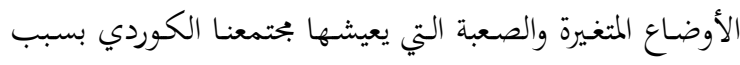

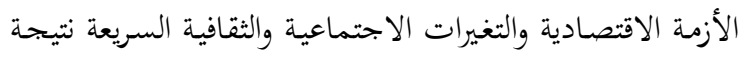

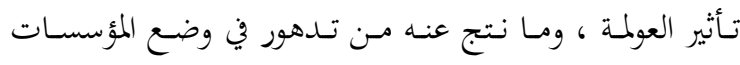

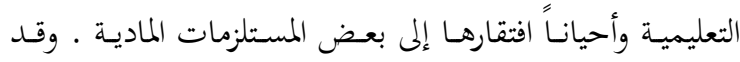

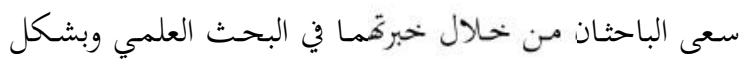
خاص في موضوع طرائق التدريس ، إلى تقديم دراسة متخصصة لئحس

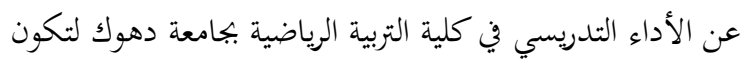
فاتحة لسلسلة من الدراسات عن الأداء التدريسي بشقيه النظري لتري أمـا الأهمية التطبيقية للدراسـة الحاليـة فإهـا تكمـن في إلقـاء

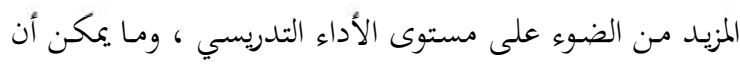
تسفر عنها من نتائج تساعد اصحاب القرار في هذه المؤسسات 
ويعتبر تقويم عضو هيئة التدريس من البمالات التي يجب الاهتمام

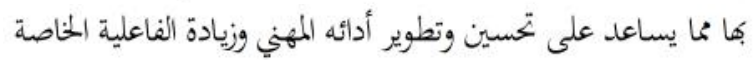

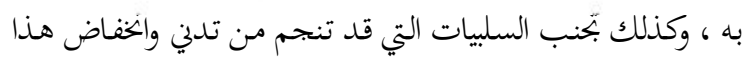

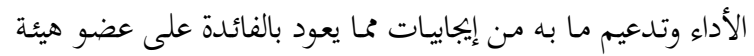
التدريس ذاته، وكذلك على جميع العناصر المستفيدة من هذا الأداء.

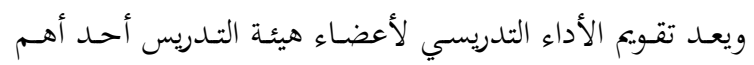
ركائز عملية الاعتماد الأكاديمي للجامعات ، حيث لادئ تسعي كثير

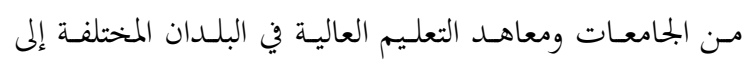
تطوير أداء أعضاء هيئة التدريس بها، وذلك من خهلال متابعة وتقويم ممارساتم التدريسية (الحكمي ، 2004 ، 14).

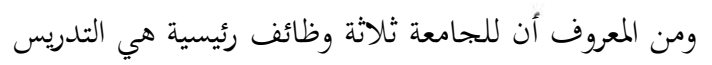

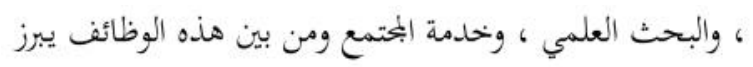
التدريس والبحث العلمي على أهما الأكثر أهمية وحيوية .

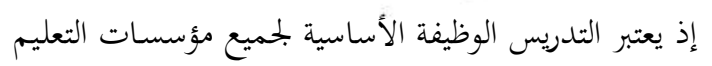

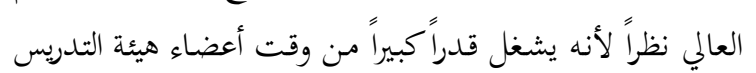

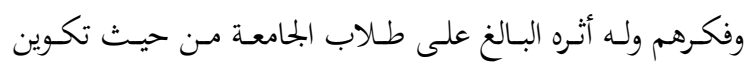

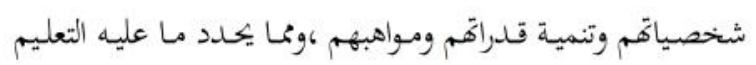

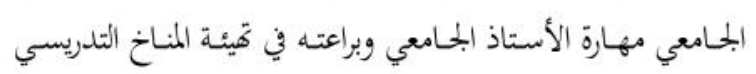
للتعلم وتنمية الإثارة الفعلية لدى طلابه والتواصل الإيجابي فيما بينه

وبينهم بالإضافة إلى إثارة دافعيتهم (الختيله ، 2000 ، 113) . ويرى يونس (Younes, 2003) أن تقويم عضو هيئة التدريس يهدف إلى أمرين متناقضين، الأول تحسين وتطوير أداء

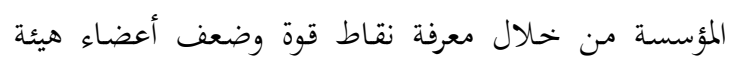
التدريس، والثاني معرفة قدرات عضو هيئة التدريس لأخذذ قرار

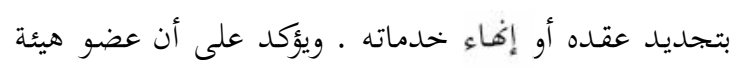
التدريس هو المفتاح للوصول إلى جودة أداء المؤسسات التعليمية

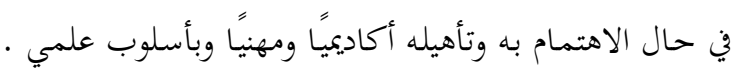

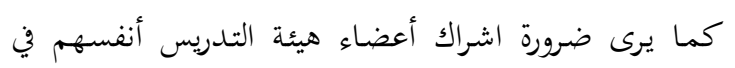

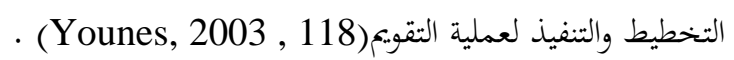

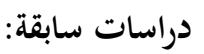

أجرى الباحثان مراجعة للأدبيات التي تناولت موضوع الأداء

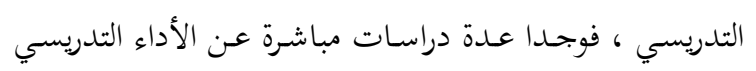

يعرف بأنه تقدير كفاءة الفرد في عمله ، بغرض معرفة مدى

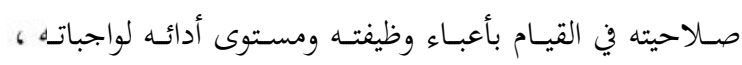

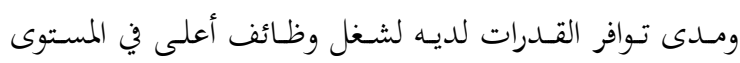

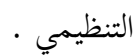
ولأغراض الدراسة الحالية يعرف الباحثان الأداء التدريسي

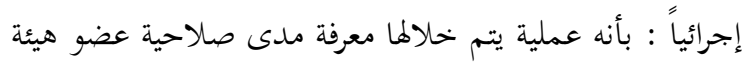

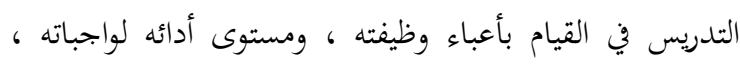

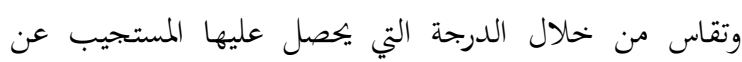

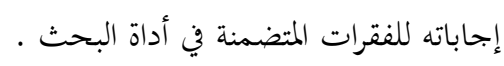

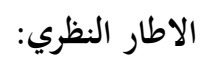

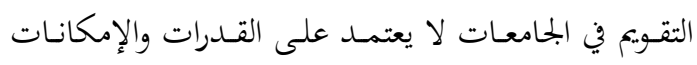

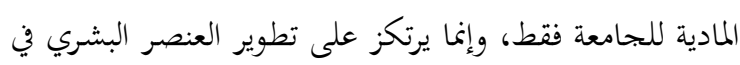
الجامعات وخحاصة عضو هيئة التدريس (شحاته والمزروع ، 2002 163 : التدريس تستخدم كلها أو بعضها في الجامعات، مثل تقويم أداء

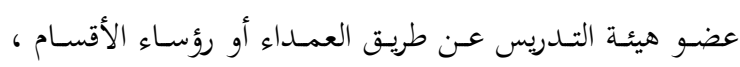
وتقويم أداؤهم عن طريق حث عضو هئ هيئة التدريس على أن يقيم

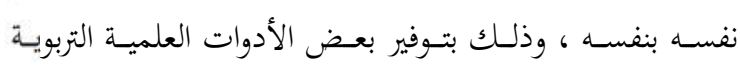

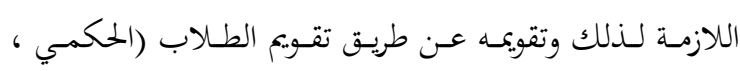

.) 14 2004

وقد ورد في دليل التقويم الذاتي والخـارجي والأعتمـاد العـام

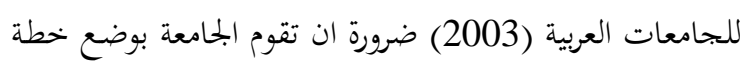

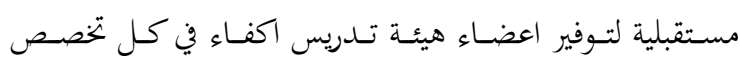
وحسب حاجـات ذلك التخصص ، وعلى ان تتضـمن الخطة

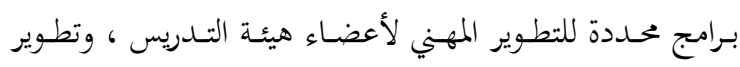

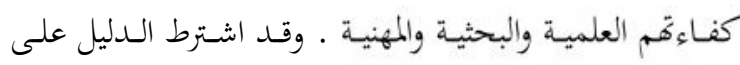
الجامعات ضرورة وجود نظم وبرامج واضحة لتقويم اعضاء الميئة

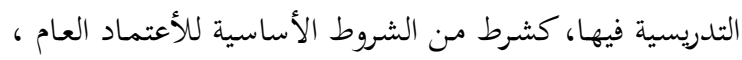

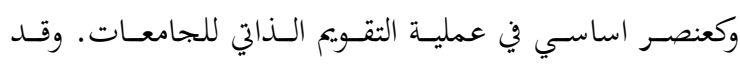

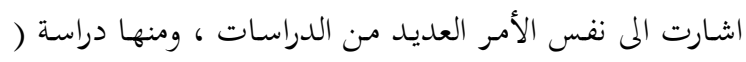
الجراح وآخرون ، 2005 ) . 


$$
\text { 3. دراسة بطاينة (2004): }
$$

(قياس أداء أعضاء هيئة التدريس في المؤسسات التعليمية).

دعت الى استخدام اسس ومعايير واضحة قابلة للقياس في

تقـويم الأداء التدريسي في الجامعسة، وهـي التـدريس، والانتساج

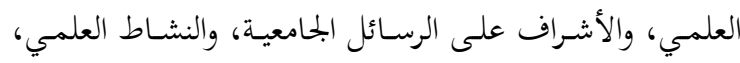

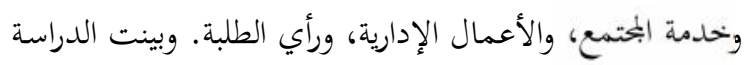

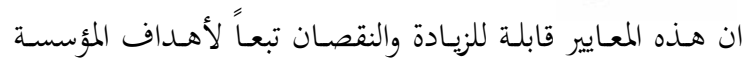
التعليمية ـ فمن الضروري تقويم اعضاء هيئة التدريس من خحلال تأشير مدى مساهتهم في تحقيق اهداف المؤسسة التعليمية. 4.دراسة درة (2005):

(نو ميثاق أخلاقي للهيئة التدريسية في الجامعات الأردنية

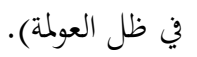

جـاءت هـــه الدراسـة في سـياق دراسـات تناولـت الجحانبب

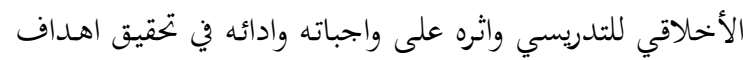

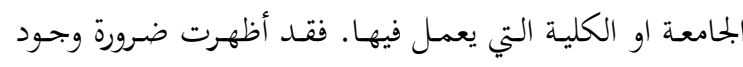
ميثاق عمل اخلاقي لأعضاء هيئة التدريس في مؤسسات التعليم

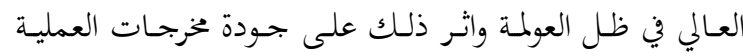
التعليمية.

ومن خلال ما تقدم من عرض يتبين لنا أن الأداء التدريسي

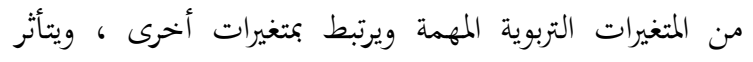
بعوامل وظروف العمل الأكاديمي ، وقد تباينت الدراسات

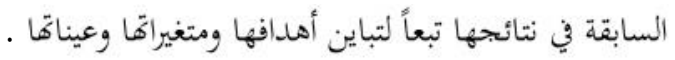
الطريقة والإجراءات

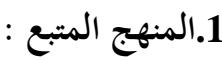

اعتمدت الدراسة الحالية على المنهج الوصفي المقارن الذي المتي

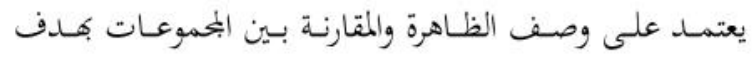

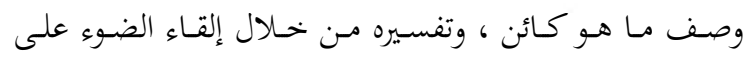

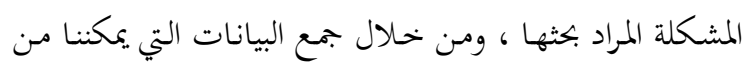
وصف الظاهرة المدروسة . إذ يمكن تعريف المنهج الوصفي بأنه أسلوب من أساليب التحليل المرتكز على معلومات كافية ودقيقة

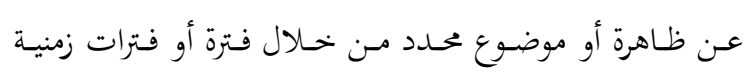

في الجامعات ، وعليه سيتم عرض بعض الدراسات التي يمكن

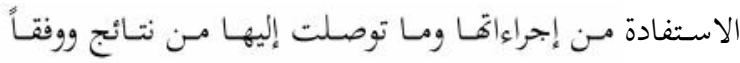
للتسلسل الزمني . 1. (1) دراسة السر(2003):

(تقويم جودة قدرات التدريس الجامعي لدى اساتذة جامعة

الأقصى في غزة")

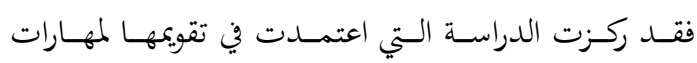
التـدريس لأسـاتذة جامعة الأقصى في غزة على اربعة بحسالات وهي مهارات التخطيط للتدريس، ومهارات تنفيذ التدريس، ومهارات تقويم تعلم الطلبة وتقديم التغذية الراجعة، ومهارات الاتصال والتواصل مع الطلبة واعتمدت الدراسة على استبانة أعدها الباحث تكونت من 72 فقرة موزعة على أربعة جوانب، ولكي،

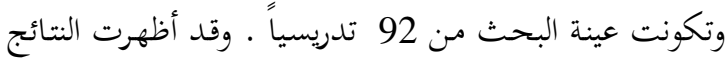
أن متوسطات التقديرات التقويمية لإجمالي للمهارات، ولمهارات التخطيط ومهارات الاتصال والتواصل وصلت مستوى الجودة، غير أن متوسطي تقديراتمم لمهارات تنفيذ التدريس، ولمهارات التقويم لم ييلغا مستوى الجودة ـ ووجد أن هناك أثر ذو دلالة لمتغير المؤهل على تقديرات جودة مهارات التدريس.

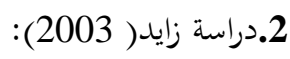
(ضمان جودة التعليم العالي من خلال تقويم الأداء الجامعي - دراسة تحليلية :قياس أداء أعضاء الهيئة التدريسية). أشارت الدراسة إلى وجود ارتباط وثيق بين مفهوم الجحودة ومبدأ التطور المستمر للمؤسسة الأكاديمية، وخاصة في أداء عضو هيئة التدريس ومدى ارتباط ذلك بأهداف الجامعة المعلنة . واقترح في دراسته أسلوبًا غير تقليدي لقياس تقويم أداء أعضاء

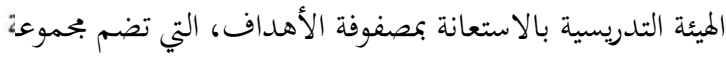

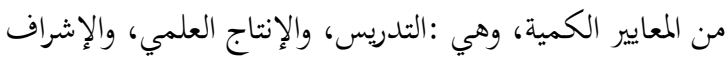

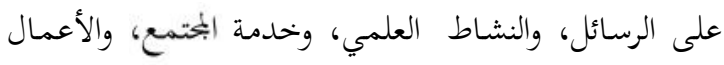

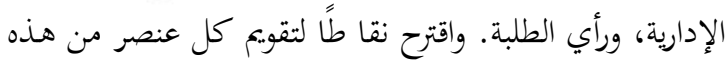

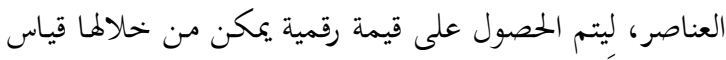

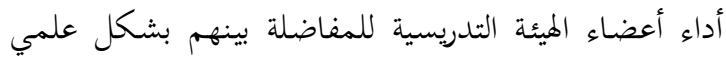


التربية الرياضية بجامعة دهـوك للعام الدراسي (2018-2019)

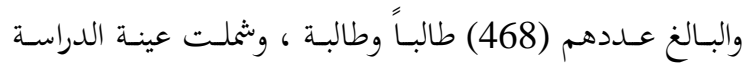

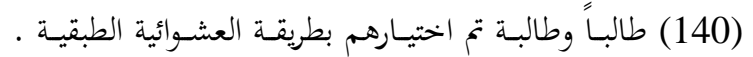

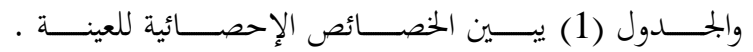

معلومـة ، وذلكك مسن أجـل الحصـول على نتـائج عمليـة يتم

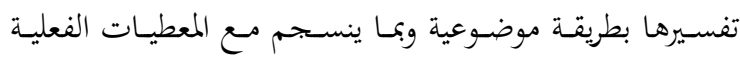

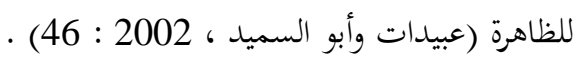

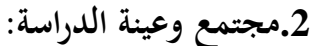

يتكون بجتمع الدراسة من طلبة الدراسة الصباحية في كلية جدول (1): توزيع أفراد العينة تبعاً للمتغيرات الديغرافية

\begin{tabular}{|c|c|c|c|}
\hline النسبة الدئوية & العدد & المتغير & \\
\hline & & & العمر: \\
\hline 26.4 & 37 & 20-20سنة & \\
\hline 58.6 & 82 & 23-21سنة & \\
\hline 15.0 & 21 & 26-24سنة & \\
\hline & & & لجنس: \\
\hline 60.7 & 85 & ذكر & \\
\hline \multirow[t]{2}{*}{39.3} & 55 & أنثى & \\
\hline & & & لصف: \\
\hline 25.0 & 35 & الأول & \\
\hline 25.0 & 35 & الثاني & \\
\hline 25.0 & 35 & الثالث & \\
\hline \multirow[t]{2}{*}{25.0} & 35 & الرابع & \\
\hline & & & لخافية الدراسية: \\
\hline 52.1 & 73 & & علمي \\
\hline 47.9 & 67 & & أدبي \\
\hline
\end{tabular}

الاختبار ( علام، 2001 ، 277 ). إذ يشير إيبل

3.أداة الدراسة:

(Ebel,1972) اعتمـدت الدراسـة الحاليـة في جمـع البيانـات وقيـاس مستوى

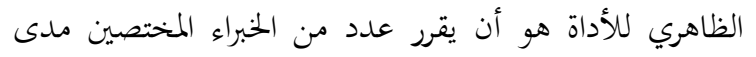
تمثيل الفقرات للصفة، أو الخاصية المراد قياسها (قادر، 2013 :

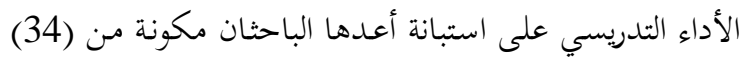

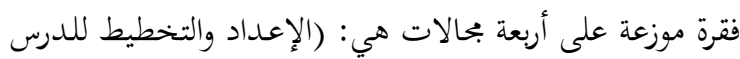
.$(46$

وعليـه تحقـق الباحثـان مـن صـدق الأداة عـن طريق إيجاد

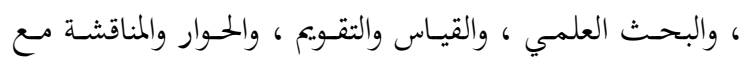

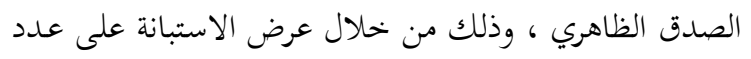

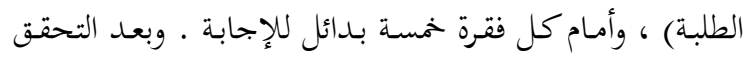
من المختصسين في بحال طرائق التدريس والعلوم التربوية والنفسية ولنية

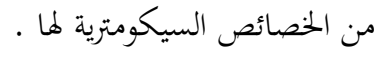

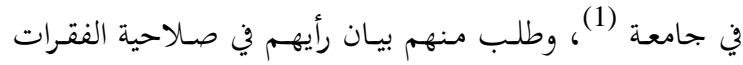

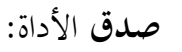

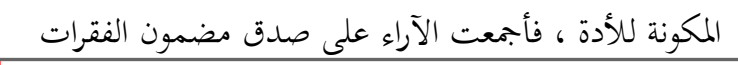
يقصد به مدى ملائمة الدرجات المستمدة من الاختبار

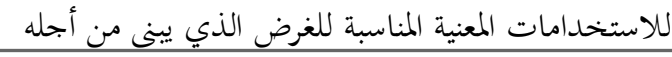

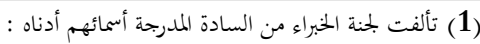

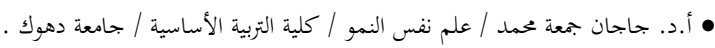

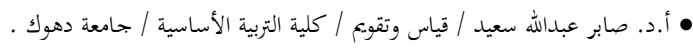

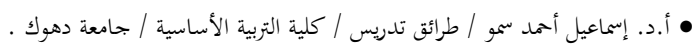

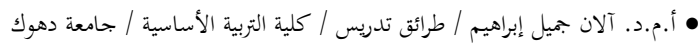

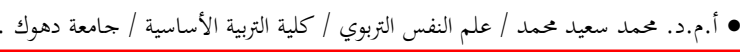


3.الاختبـار التـائي لعينتين مستقلتين لإجـــاء المقارنـة في الأداء

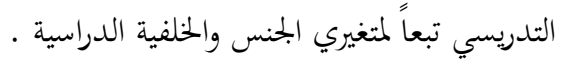

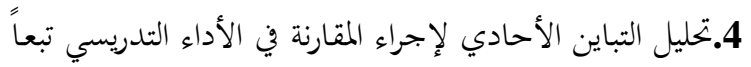

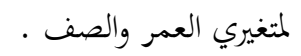

\section{نتائج البحث ومناقشتها}

\section{1.النتائج المتعلقة بالهدف الأول:} لما كان الهدف الأول في البحث يسعى إلى معرفة مستوى الإن

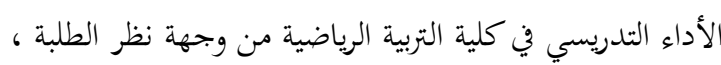
عليه تمت معالجة البيانات إحصائياً وتبين أن درجات أفراد العينة

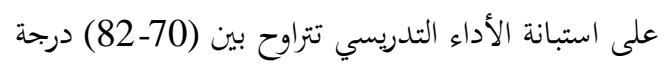
بمتوسط حسابي قدرهُ(75,42) درجة وبانحراف معياري بلغ

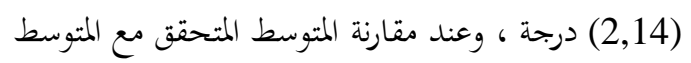
الفرضي للأداة البالغ (68) درجة باستخدام الاختبار التائي لعينة واحدة تبين أن الفرق دال عند مستوى دلالة (0,001) ولصالح المتوسط المتحقق مما يدل على أن مستوى الأداء

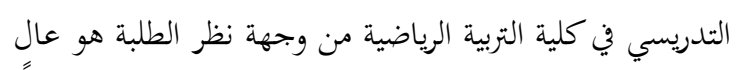
، والجدول (2) يوضح ذلك .
وصـاحيتها لقيـاس مستوى الأداء التدريسي مـن وجهـة نظـر

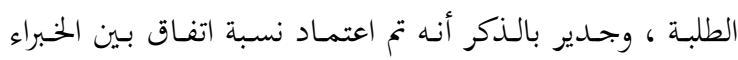
(\%80) فأكثر معياراً لقبول الفقرة .

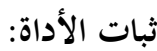

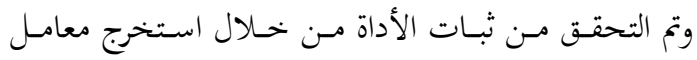
الثبات بطريقة الاختبار وإعـادة تطبيقه ، إذ تم تطبيق الاستبانة على عينة تألفت من (20) طالباً وطالبة تم اختيارهم عشوائياً

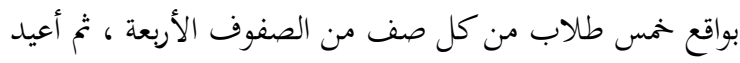

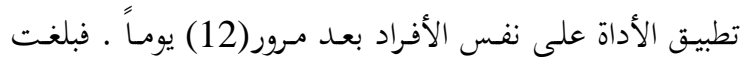
معاملات الارتباط بين التطبيقين بحسب بحالات الأداة (0,84

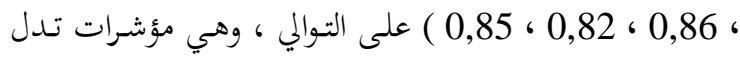

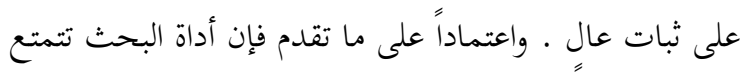
بالصلاحية لتوفر الخصائص السيكومتريه فيها . 4.الوسائل الإحصائية: تمتت معابلحة البيانات الواردة في الدراسـة باستخدام برنامج

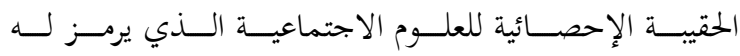
باختصـار(SPSS) ، واعتمـــ الباحثـان الوســائل الإحصـائية

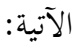
1.التكرارات والنسب المئوية لتحديد خصائص العينة. 2.الاختبار التائي لعينة واحدة لتحديد مستوى الأداء التدريسي.

\begin{tabular}{|c|c|c|c|c|c|c|}
\hline مستوى الدلالة & القيمة التائية & المتوسط الفرضي & الانحراف المعياري & المتوسط المتحقق & العدد & المتغير \\
\hline 0,001 & 3,46 & 68 & 2,14 & 75,42 & 140 & الأداء التدريسي \\
\hline
\end{tabular}

\section{أ.دلالة الفروق تبعاً لمتغير العمر:}

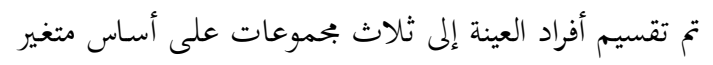

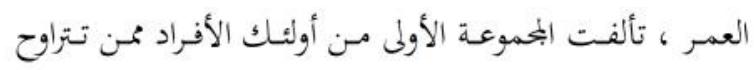

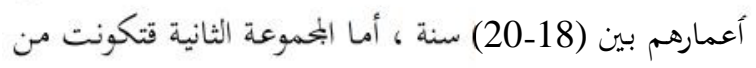

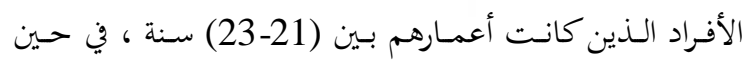

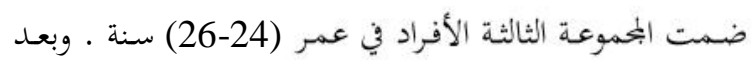
إجـراء المقارنـة بـين درجـات المجموعـات الـثلاث على الأداء
2.النتائج المتعلقة بالهدف الثاني:

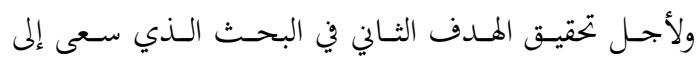

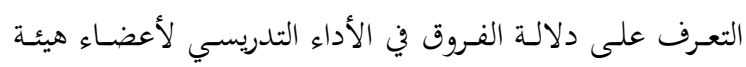

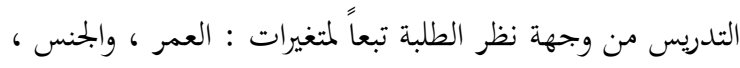

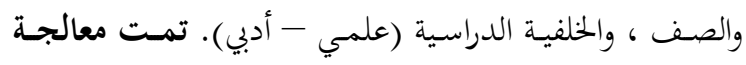
البيانات وعلى النحو الآتي: 
التدريسـي باسـتخدام تحليـل التبـاين الأحسادي (ANOVA) إذ بلغـت القيمـة الفائيسة المحسـوبة (1,886) وهـي غـير دالـة

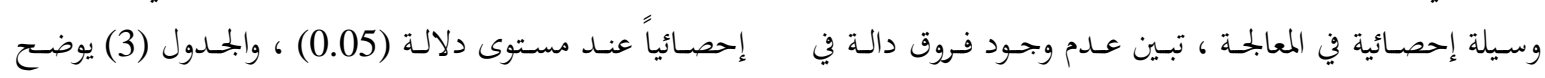
. الأداء التدريسي من وجهة نظر الطلبة يعزى إلى متغير العمر ، جدول (3): نتائج تحليل التباين الأحادي لدلالة الفرق في الأداء التدريسي تبعاً للعمر

\begin{tabular}{|c|c|c|c|c|c|}
\hline مستوى الدلالة & قيمة F & متوسط المربعات & درجات الحرية & مجموع المربعات & مصدر التباين \\
\hline \multirow{3}{*}{ غير دال عند 0.05} & \multirow[t]{3}{*}{1,886} & 8,524 & 2 & 17,048 & 吾 \\
\hline & & 4,519 & 137 & 619,087 & داسلل الهمبوعات \\
\hline & & & 139 & 636,135 & 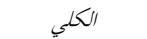 \\
\hline
\end{tabular}

وبجدف معرفة دلالة الفروق في درجات الأداء التدريسي من

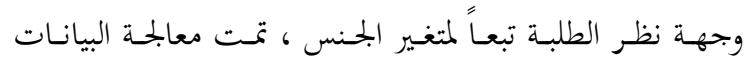

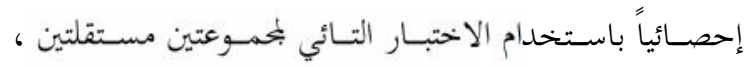
فأظهرت النتائج وجود فرق دال في الأداء التدريسي عند مستوى دلالهة (0.05) يعزى الى متغسير الجـنس ، وكـان الفـرق لصـالح

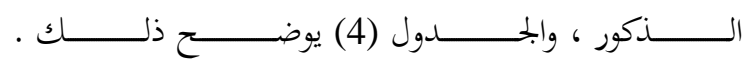

ويمكـن تفسير هـــه النتيجــة في أن الأفـراد في البحموعـات العمرية الثلاث يعيشون في نفس الأجواء الدراسية ، ويتعرضون

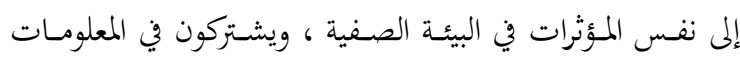

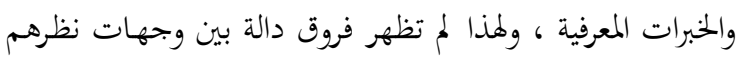

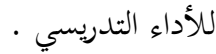
ب.دلالة الفروق تبعاً لمتغير الجنس: ل جدول (4): نتائج الاختبار التائي للالالة الفرق في الأداء التدريسي تبعاً للجنس

\begin{tabular}{|c|c|c|c|c|c|}
\hline مستوى الدلالة & قيمة ت المحسوبة & الانحراف المعياري & متوسط الدرجات & العدد & المجموعة \\
\hline \multirow[t]{2}{*}{0,05} & 3,010 & 2.276 & 75,847 & 85 & ذ كور \\
\hline & & 1,732 & 74,763 & 55 & إناث \\
\hline
\end{tabular}

الثالثـة الطلبـة الدارســين في الصـف الثالـث ، بينمــا تكونـت

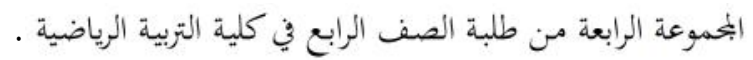
وبعد إجراء المقارنة بين درجات البحموعات الأربع على الأداء التدريسي باسـتخدام تحليـل التبـاين الأحسادي (ANOVA)

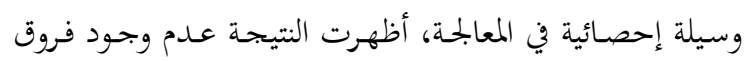
دالة في الأداء التدريسي مـن وجهة نظر الطلبة يعزى إلى متغير الصف الدراسي ، إذ بلغت القيمـة الفائية المحسوبة $(2,557)$ وهي غير دالة إحصائياً عند مستوى دلالة (0.05) ، والجحدول . ذح يوض (5)
وعمومـاً يمكـن تفسير هـذه النتيجـة في أن أفراد العينـة مـن

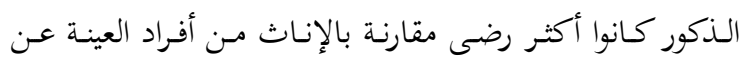

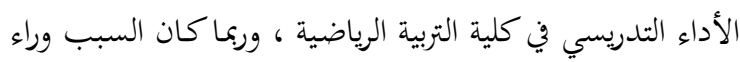

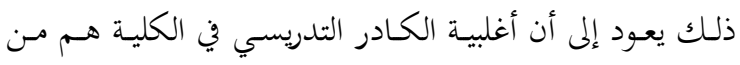
· الذكور

\section{ج.دلالة الفروق تبعاً لمتغير الصف:} تم تقسيم أفراد العينة إلى أربع بجموعات على أسماس متغير لهير

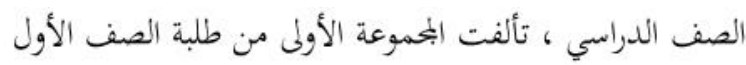

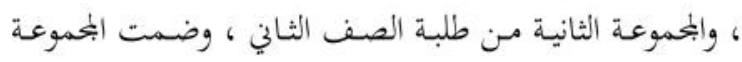




\begin{tabular}{|c|c|c|c|c|c|}
\hline مستوى الدلالة & قيمة F & متوسط المربعات & درجات الحرية & مجموع المربعات & مصدر التباين \\
\hline غير دال & 2,557 & 11,321 & 3 & 33,964 & 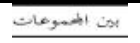 \\
\hline \multirow{2}{*}{ عند 0.05} & & 4,428 & 136 & 602,171 & ماسل الهموعات \\
\hline & & & 139 & 636,135 & الكلي \\
\hline
\end{tabular}

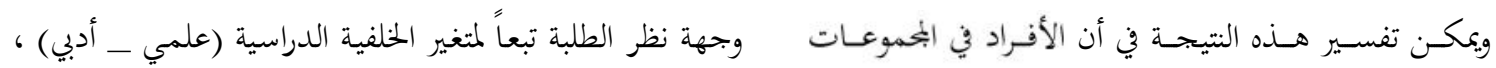

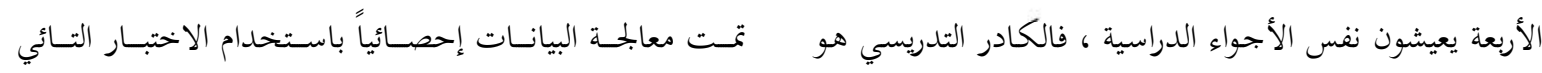

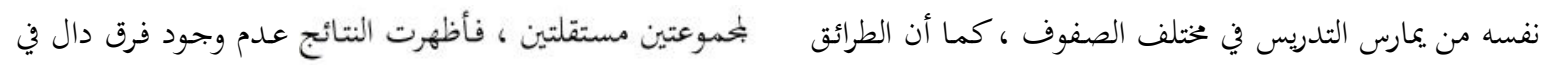

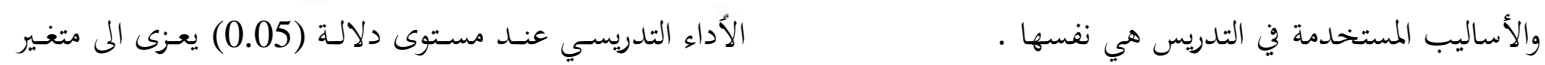

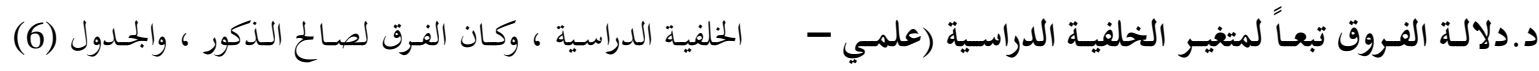

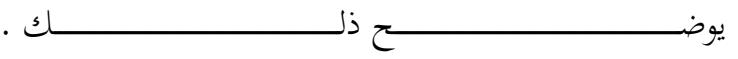

وبهدف معرفة دلالة الفروق في درجات الأداء التدريسي من

جدول (6): نتائج الاختبار التائي لدلالة الفرق في الأداء التدريسي تبعاً للخلفية الدراسية

\begin{tabular}{|c|c|c|c|c|c|}
\hline مستوى الدلالة & قيمة ت المحسوبة & الانحراف المعياري & متوسط الدرجات & العدد & المجموعة \\
\hline \multirow[t]{2}{*}{ غير دال عند 0,05 } & 0,692 & 2,246 & 75,301 & 73 & علمي لمي \\
\hline & & 2,024 & 75,552 & 67 & أدبي \\
\hline
\end{tabular}

3. هنـاك تبـاين في وجههات نظر الجنسـين مـن الطلبة لمستوى الأداء التدريسي لأعضاء هيئة التدريس في الكلية.

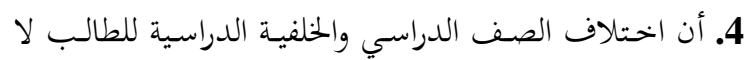

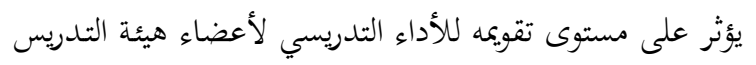
في الكلية. التوصيات : واسـتكمالاً للفائـدة المتوخهـاة مـن الدراسـة الحاليـة يوصسي الباحثان بالآتي: 1.ضرورة قيام كليات التربية الرياضية بتشجيع التدريسيين على بلى

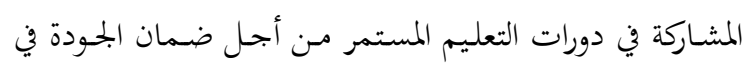
الأداء التدريسي المقدم في هذه الكليات .

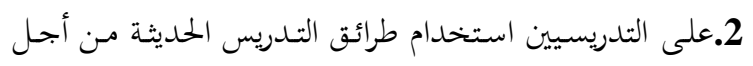
زيادة فاعلية التدريس وديمومة مشاركة الطلبة في الأنشطة الصفية واللاصفية .
ويمكـن تفسير هـذه النتيجـة في أن أفراد العينة مـن خريجي الفرع العلمي لا تتباين وجهة نظر حول الأداء التدريسي في كلية

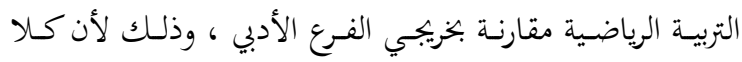

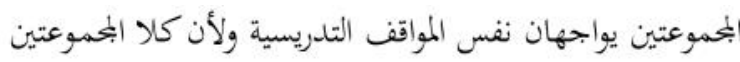
يعملان معاً في الصف أو في الملاعب أثناء التطبيقات العملية . وعليه فإن وجهة نظرهما جاءت متماثلة ولم تؤثر الخلفية الدراسية على وجهات نظرهم إزاء الأداء التدريسي .

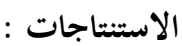
يمكننا أن نستتتج من النتائج التي أسفر عنها البحث الآتي:

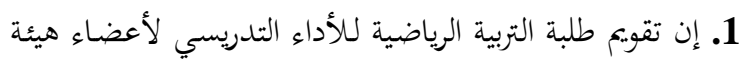
التدريس في الكلية كان ايجابياً . 2. أن متغـير عمـر الطالب لا يـؤثر على مستوى تقويمهـ لأداء التدريسيين من أعضاء هيئة التدريس من وجهة نطر الطلبة . 
المملكة العربية السعودية، العدد التسعون، السنة الرابعة والعشرون، ص ص ص $.56-13$

6.حمدان، محمد ، 2005،" واجبات عضو هيئة التدريس"، ملتقى التعليم العالي والعولمة :نحو ميثاق عمل أخلاقي، وزارة التعليم العالي والبحث

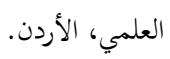
7.الحنيطي، عبد الرحمن، محمو د، سامي، الجابر، أحمد، وبطاينة، منذر(2005): نوعية التعليم والمواءمة"، ورشة عمل المحور الثاني للمؤتمر الوطني للتعليم العالي والبحث العلمي، جامعة عمان الأهلية، الأردن. 8.الخثيلة، هنـد ماجـد (2000م )، مصـادر ضغوط العمل كمـا يـدركها العاملون في التعليم الجحامعي، بحلة جامعة الملك سعود، م9، العلوم التربوية،

$$
\text { الدراسات الإسلامية، ص ص 85_112. }
$$

9.درة، عبد الباري إبراهيم ، 2005 ،" نخو ميثاق أخلاقي للهيئة التدريسية في الجامعات الأردنية في ظل العولمة"، ملتقى التعليم العالي والعولمة :نحو ميثاق عمل أخلاقي، وزارة التعليم العالي والبحث العلمي،

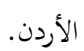

10.زايد، عبد الناصر ،2003،" ضمان جودة التعليم العالي من خحلال تقويم الأداء الجامعي- دراسة تحليلية :قياس أداء أعضاء الهيئة التدريسية"، مؤتمر ضمان الجودة وأثره في أداء كليات الاقتصاد، جامعة الزرقاء الأهلية،

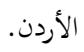
11.زين الدين, محمد محمود(2007). كفايات التعليم الالكتروني. جدة: دار خوارزم العلمية للنشر. 12.السر، خالد خميس( 2003): تقويم جودة قدرات التدريس الجامعي

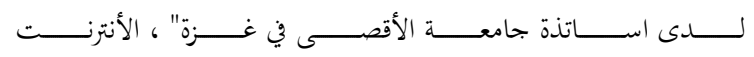
www.alaqsa.edu.ps/ar/aqsamagazine/eight_2/8. pdf 13.شحاته، حسن، والمزروع ، هيـا ( 2002): التقويم الـذاتي لأعضـاء وقيادات كليات البنـات بالمملكة العربية السعودية، مـدخل لتطوير الأداء الجـامعي بحـث قـدم في نـدوة تطوير عضو هيئة التـدريس، جامعـة الملكك سعود، مركز الدراسات الجامعية للبنات ، ص ص 163-201.
3.ضرورة قيام كليات التربية الرياضية بتوفير الدعم المادي وتوفير المستلزمات الرياضية لضمان الجودة في الأداء التدريسي . 4.على وسائل الإعلام إبراز الجانب الايجابي في الأداء التدريسي في كليـات التربيـة الرياضـية مـن أجــل إثـراء الحيـاة الاجتماعيـة والثقافيـة ومـن خـلال ابـراز دور المؤسسـات التعليميـة في خدمـة

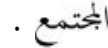
5.العمـل مـن أجــل إشـاعة ثقافـة جـودة الأداء في المؤسسـات التعليمية ومنها كليات التربية الرياضية عن طريق استمرار مشاركة الطلبة في تقويم الأداء .

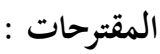
أخسيراً ، يـرى الباحثــان أن هنــاك حاجـة لإجــراء المزيــ مـن الدراسات في هذا ابحال بهدف إبراز دور كليات التربية الرياضية في خدمـة المؤسسـات الرياضسية في إقلـيم كوردستان ، ولأجـل تسليط الضوء على المتغيرات المؤثرة في الأداء التدريسي .

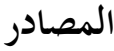

1.بـو لبـده ، سـبع محمــ (1996م)، مبـادئ القيـاس النفسـي والتقيـيم التربوي ، عمان ، جمعية عمال المطابع التعاونية ، الطبعة الرابعة. 2.برنامج الأمم المتحدة للتطوير ، 2005 ، تقييم نوعية وتأثير البر امج الأكاديمية - دليل مراجعة موضوع أكاديمي، صندوق الأمم المتحدة

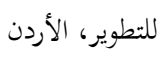
3.بطاينة، منذر(2004 ): " قياس أداء أعضاء هيئة التدريس في المؤسسات التعليمية"، مديرية المتابعة وضبط الجودة، وزارة التعليم العالي والبحث العلمي، الأردن 4.الجراح، عمر، أبو الرب، عماد، الخوالدة، خليف، وبطاينة، منذ ر ، 2005، دليل إعداد تقرير التقويم الذاتي لبرنامج أكاديمي، وزارة التعليم

$$
\text { العالي والبحث العلمي، الأردن }
$$

5.الحكمي، إبراهيم الحسن (1424هـ - 2004م )، الكفـاءات المهنية المتطلبة للأستاذ الجامعي من وجهة نظر طلابه وعلاقتها ببعض المتغيرات، بحلة رسـالة الخليج العربي، مكتـب التربية العربي لـدول الخليج، الريـاض، 
18.قادر، ئيفان أبو بكر(2013): تطور مشاعر الألفة وعلاقته بالسلوك

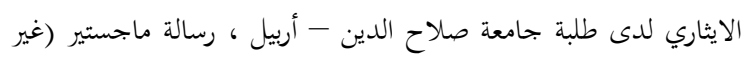

$$
\text { منشورة) ، كلية الآداب ، جامعة صلاح الدين. }
$$

19.Kanji, G. K (1999), "Total Quality Management in UK Higher Education Institution", Total Quality Management, Vol. 19, P.24.

20.Marsh, H. and Roche, L. (1993).: The use of students evaluations and an individually structured interentional enhance university teaching effectiveness American Educational Research Journal Vol, 30 . PP 217-250.

21.Younes, Bassem (2003), "Faculty Evaluation: Towards a Happy Balance Between Competing Values", World Transactions on Engineering and Technology Education, Vol. 2, No. 1, pp. 117120.

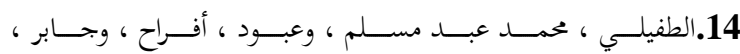

$$
\begin{aligned}
& \text { انتظار(2013): تقويم جودة أداء اعضاء هيئة التدريس في كلية الهندسة - } \\
& \text { جامعة بابل ضمن مؤشري التخطيط والتنفيذ ، بحلة جامعة بابل ، العلوم }
\end{aligned}
$$

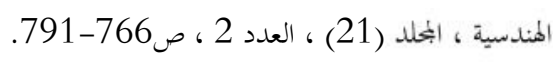

$$
\begin{aligned}
& \text { 15.عبيدات ، ذوقان ، وأبو السميد، سهيلة(2002): البحث العلمي : }
\end{aligned}
$$

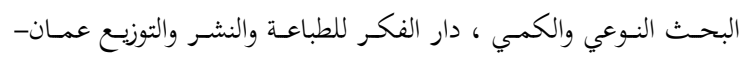

$$
\begin{aligned}
& \text { الاردن. } \\
& \text { 16.عـلام، صــالح الـــين محمـود(2001):القيساس والتقـويم التربـوي } \\
& \text { والنفسي: أساسياته وتطبيقاته وتوجهاته المعاصرة ، دار الفكر العربي ، } \\
& \text { القاهرة . } \\
& \text { 17.غيث، عبد السلام وقدادة، عيسى ،2005،" الاعتماد وضمان }
\end{aligned}
$$

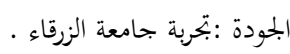

\title{
EVALUATING THE TEACHING PERFORMANCE FOR THE STAFF MEMBERS IN PHYSICAL EDUCATION COLLEGE FROM THE PERSPECTIVE OF STUDENTS
}

\author{
Pro.Dr. Ahmed Qasem Mohammad and Sabri Sulaiman Hassan \\ College Of Physical Education, University Of Duhok, Kurdistan Regiom-Iraq
}

\begin{abstract}
The study aimed to identify the level of teaching performance of staff members in college of Physical Education at the University of Duhok, and to identify the significance of differences in the teaching performance of college members according to the variables of age, sex, grade and academic background (scientific - theoretic). The sample of the study included (140) male and female students selected by random stratified sample among the students of the college of Physical Education at the University of Duhok.

The study was based on a questionnaire consisting of (34) paragraphs distributed over four areas (preparation and planning of the lesson, scientific research, measurement and evaluation, dialogue and discussion with students), and each paragraph has five alternatives to answer, after checking its psychometric properties.

Data were processed using Pearson correlation coefficient, T-test of two independent samples, and mono-variance analysis.

In conclusion, the results showed that the level of teaching performance of college staff members in general was moderate, and the results revealed that there are significant differences in the point of view for students on the teaching performance of college staff members due to the gender variable. The results did not show any significant differences in teaching performance from the students' point of view due to age, grade and background variables. According to the results, a set of recommendations and proposals were presented.
\end{abstract}

